\title{
The contribution of plastinates to teaching complex anatomy of the heart
}

\author{
${\text { Güneş Aytaç }{ }^{1,2} \text { (D), Eren Öğüt }}^{3}$ (D), Rahime Şekerci ${ }^{4}$ (D), Sezgi Gürçay ${ }^{5}$ (D), Nurettin Oğuz ${ }^{4}$ (D), \\ Muzaffer Sindel ${ }^{4}$ iD \\ ${ }^{1}$ Department of Anatomy, School of Medicine, TOBB University of Economics and Technology, Ankara, Turkey \\ ${ }^{2}$ Department of Anatomy, Biochmistry \& Physiology, John A. Burns School of Medicine, University of Hawai'i at Mãnoa, Hawaii, USA \\ ${ }^{3}$ Department of Anatomy, School of Medicine, Bahçȩsehir University, İstanbul, Turkey \\ ${ }^{4}$ Department of Anatomy, School of Medicine, Akdeniz University, Antalya, Turkey \\ 'Department of Anatomy, School of Medicine, Mustafa Kemal University, Hatay, Turkey
}

\begin{abstract}
Objectives: The use of plastination can minimize health risks and cost in anatomy laboratories. Plastinates are easy to handle and can facilitate the learning of complex anatomical structures. Therefore, we aimed to evaluate the contribution of plastinates to teaching complex anatomy of the heart.

Methods: Standard S10 technique was used for heart plastination by fixation, dehydration, impregnation and curing stages. Ninety volunteer first-year medicine students at Akdeniz University, who did not take cardiovascular system anatomy lectures yet, were included. Formalin-fixed heart specimens were used in the lecture of group 1; both formalin-fixed heart specimens and heart plastinates were used in the lecture of group 2. After the lecture, a 10-question exam was administered. Statistical significance between the scores of the two groups was tested with one sample t-test, and post hoc Tukey test was used for multiple comparisons.

Results: The pre-test scores of the groups were compared with the scores obtained after the 2 hours of lecture ( $p=0.002$, $p<0.05)$. The test scores of both groups increased significantly after the lecture $(p<0.05)$. The post-test scores of group 2 were significantly higher than group $1(p=0.047, p<0.05)$. The average test scores of those trained with formalin-fixed specimens increased from $23.78 \pm 1.94$ to $48.22 \pm 3.19(p<0.05)$. Students gave positive feedback about heart plastinates, and they stated that their rising interest in the anatomy lecture due to the odourless, disinfected and reusable materials.
\end{abstract}

Conclusion: In conclusion, besides being cost-effective, healthy, long lasting and easy to maintain materials, plastinates are useful tools to teach complex anatomical structures.

Keywords: anatomy; COVID-19; medical education; plastinate; plastination

Anatomy 2021;15(1):69-75 C2021 Turkish Society of Anatomy and Clinical Anatomy (TSACA)

\section{Introduction}

Anatomy as one of the basic medical sciences is fundamental for medical training. In particular, anatomy is necessary for surgical disciplines that the spatial relationships of the structures with one another should be very well known. The basic teaching tools used for teaching anatomy are cadavers, anatomical models, written materials (such as books, atlases, posters), video images and computer programs. ${ }^{[1]}$ Cadavers have been essential for physicians to have a through understanding of the human morphology and have played a crucial role in medical education. Dissections of the cadavers provide an excellent opportunity to recognize the three-dimensional structure of the body. ${ }^{[2]}$ However, some issues make difficult to study with cadavers such as scarcity of cadavers, decreased cadaver donations, and increased number of students. ${ }^{[3-5]}$ Anatomical models are another commonly used anatomy education material. However,

This study was a poster presentation at 20th National Anatomy Congress, 27th-31st August 2019, Istanbul, Turkey. 
anatomical models are not show the variations and they are expensive because of importation. Two-dimensional educational materials such as textbooks, drawings and digital images, may be of limited benefit in understanding the three-dimensional complexity of the anatomy and spatial relationships of the structures. ${ }^{[1]}$

Another important issue to highlight is that, although anatomy is essential for diagnosis and treatment, medical school students graduate with inadequate anatomy knowledge ${ }^{[6]}$ Various studies evaluating the adequacy of anatomy education have shown that anatomy knowledge of medical graduates is deficient. ${ }^{[3,4,7]}$ Therefore, it has become compulsory to search effective alternative or supportive tools for teaching anatomy. ${ }^{[8-10]}$ In the last two decades there has been a growing interest in plastination techniques. Plastination is a great method for long-term preservation of anatomical specimens. With plastination, it is possible to protect the anatomical materials in a durable, aesthetic and realistic manner. In this technique, curable polymers in a special vacuum process replace tissue fluids. The specimens are dry and odorless after this process. Moreover, plastinates can be manipulated without personal protective equipment. ${ }^{[11]}$ Although plastination could not be replaced by traditional cadaver training, it is an important auxiliary method ensures that the materials remain intact for a long time. Plastinates provide a learning tool that converts two-dimensional textbook images into three-dimensional model..$^{[5,12,13]}$ Therefore, plastinated specimens are valuable in teaching anatomy ${ }^{[10,14,15]}$ Beyond the educational benefits, plastination stops the reactions inside the body and prevents the degradation and dehydration of the materials. In this way, plastinates remain intact much longer than formalin fixed cadavers do. These materials do not deteriorate over time and save dissection hours.

Another important issue is the risk of transmitting SARS-CoV-2, the virus causing COVID-19, from dead bodies is not yet known. ${ }^{[16]}$ People should be notified not to touch the body if it was recognised or presumed that the deceased was infected with COVID-19; it is not yet understood how long the virus will remain on human tissue and dead bodies. As with other infectious diseases, the cause of death should be communicated to all those who will be handling the body via the medical certificate of death. Equipment and material cleaning, as well as individual hygiene, are essential parts of safety during the pandemic. ${ }^{[17]}$ Therefore disinfected and sanitised plastinates are alternative options for the anatomical education during the COVID-19 pandemic period when considering their hygienic properties.

One of the most difficult organs for students to understand is the human heart with its complex physiol- ogy and detailed anatomy. Knowledge of the basic anatomy and physiology of the heart is essential. It is very difficult in formalin fixed specimens to show the detailed anatomy of the heart valves without damaging the structures. ${ }^{[18]}$ Therefore, in this study, we aimed to investigate if the heart plastinates contribute to anatomy education of the under graduate medical students.

\section{Materials and Methods}

Standard S10 technique, which was previously defined in the literature, was used for plastination. Fresh sheep hearts were plastinated by fixation, dehydration, impregnation and curing stages. ${ }^{[18]}$ Heart specimens have gained light and flexible structure after plastination process and become dry, odourless and resistant to deterioration (Figure 1). Structures including chordae tendinea, papillary muscles, right and left atrioventricular orifice, bicuspid (mitral) and tricuspid valves, pulmonary veins, aortae, coronary vessels, and their relations with each other were described in heart plastinates in details (Figures 1 and 2).

Ninety volunteer first-year students in the School of Medicine (Akdeniz University), who did not take cardiovascular system anatomy lectures yet, were included in the study. This study was conducted in accordance with the Helsinki Declaration. All protocols were approved by the Clinical Research Ethics Committee of Akdeniz University (Number: 70904504-98). Furthermore, written informed consent was obtained from the students.

A pre-test consisting of ten questions was applied to the students in order to determine their knowledge about cardiac anatomy, and then they divided into two equal groups according to pre-test results. Thus, there was no significant difference between the two groups' knowledge levels. Both groups were given a 2-hour identical lecture regarding the anatomy of the heart by the same instructor. Formalin-fixed heart specimens were used in the lecture of group 1. Formalin-fixed heart specimens and plastinated hearts were used in the lecture of group 2. After the lecture, a 10-question exam was administered to both groups. In this exam, open-ended and multiple-choice questions were prepared in order to test the student's knowledge levels. In this test, questions including atrial and ventricular structures, heart valves, and heart vessels were asked to students. The same anatomy instructor who was blinded to the study evaluated test scores.

The data were analyzed with SPSS (Version 25.0, Armonk; NY, USA). Descriptive statistics of continuous variables, such as test scores of the students, were given with mean, standard deviation, minimum and maximum 

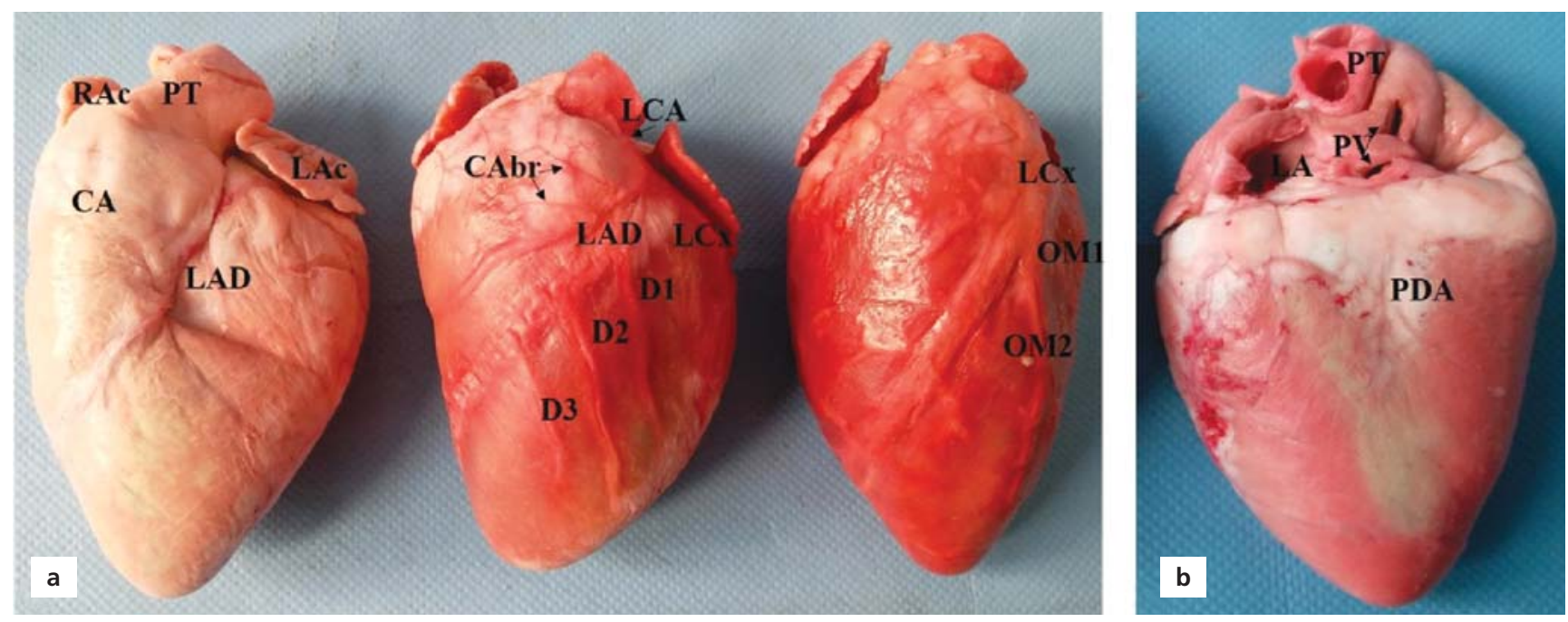

Figure 1. External aspects of the plastinated heart. (a) Anterior long-axis view. (b) Posterior view. CA: conus arteriosus; CAbr: branches for conus arteriosus; D: diagonal branches; LA: left atruium; LAc: left auricle; LAD: left decending artery, LCA: left coronary artery; LCx: left circumflex artery; OM: obtuse marginal artery; PDA: posterior descending artery; PT: pulmoner trunk; PV: pulmoner vein; RAc: right auricle.

values, and frequency and percent for categorical variables. The Shapiro-Wilk test was used as a test of normality. The independent samples t-test was used for two independent group comparisons of normally distributed variables, and the Mann-Whitney $U$ test was used for non-normal distributed variables. Statistical significance between the scores of the two groups was tested with one sample paired t-test, and post hoc Tukey test was used for multiple comparisons. A p-value $<0.05$ was considered significant.

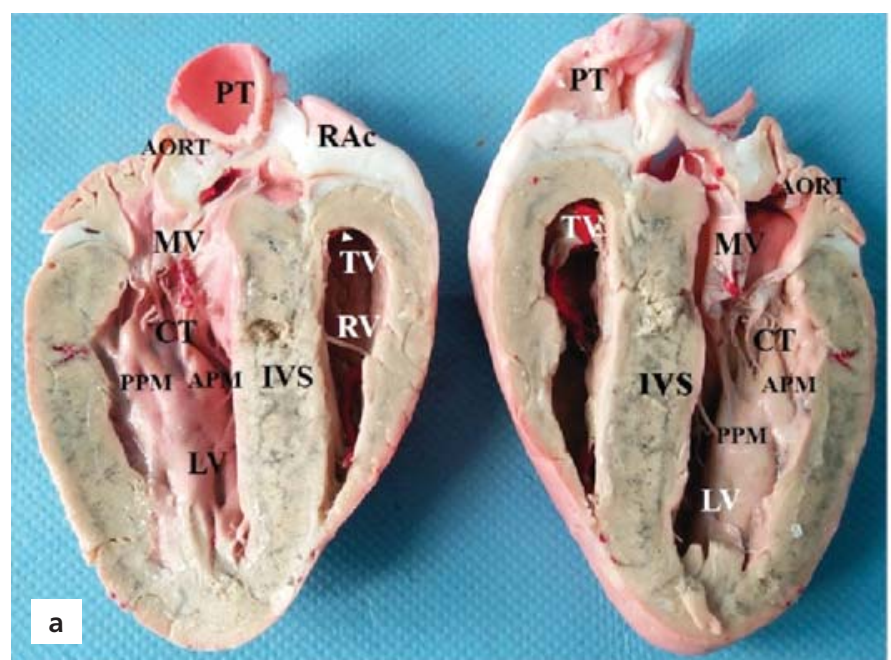

\section{Results}

The Kirkpatrick Model was used in the current study for analyzing and evaluating the results of lectures with plastinates. The evaluation model consists of four parts: reaction (level 1), learning (level 2), behavior or transfer (level 3), and results (level 4). ${ }^{[19]}$ All of the students indicated their feelings about the plastinates (level 1), and their behavior changed because of attending a lecture with plastinates. In level 2, pre-tests and post-tests were conducted to the students to measure the proper amount

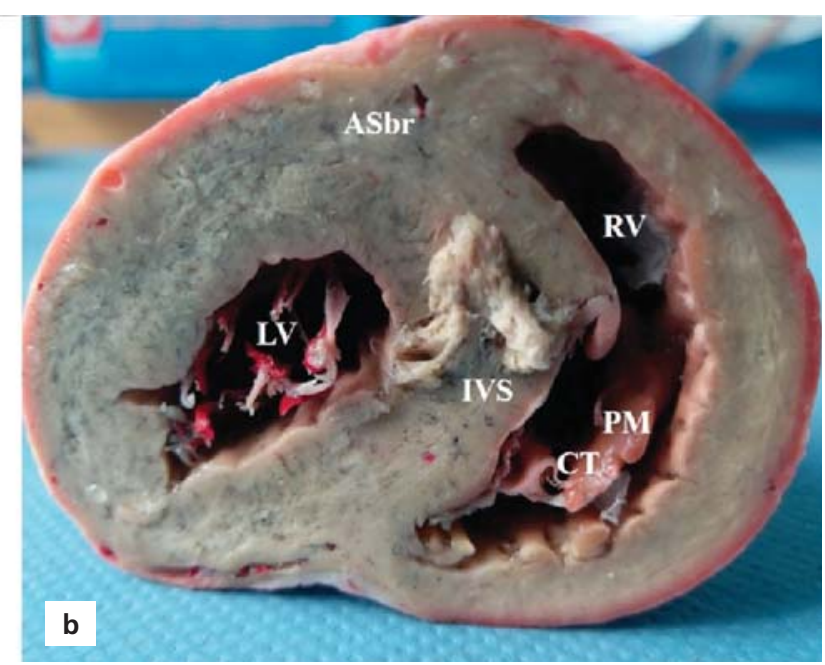

Figure 2. Internal aspect of the plastinated heart. (a) Longitudinal incision. (b) Transverse incision. APM: anterior papillary muscle; ASbr: anterior septal branches; CT: chorda tendinea; IVS: interventricular septum; LV: left ventricle; MV: mitral valve; PPM: posterior papillary muscle; PM: papillary muscle; PT: pulmonary trunk; RAc: right auricle; RV: right ventricle; TV: tricuspide valve. 
of learning that has taken place. This level gives students and us for the advancement of knowledge, skills, and attitudes based on their participation. The evaluation by Kirkpatrick's model showed that the use of plastinates in anatomy education improved the learning outcome of medical students, their level of satisfaction and the quality of anatomy education. The implications of the plastinates for anatomy education can add to the appeal and effectiveness of medical education, and that triggers active learning.

The mean values of group 1 post-test scores were $48.22 \pm 3.19$, and the mean value of group 2 was $56.89 \pm 3.52$ (Table 1). The post-test scores of group 2 were significantly higher than group $1(\mathrm{p}=0.047, \mathrm{p}<0.05)$. The test scores of the group that received lectures with both formalin-fixed specimens and plastinates were sig-

Table 1

Pre-test and post-test scores of the groups.

\begin{tabular}{|c|c|c|c|c|}
\hline & & Descriptives & Statistic & SE \\
\hline \multirow[t]{2}{*}{ Pre-test } & Group 1 & $\begin{array}{l}\text { Mean } \\
95 \% \text { Cl for mean } \\
\\
5 \% \text { trimmed mean } \\
\text { Median } \\
\text { Variance } \\
\text { SD } \\
\text { Minimum } \\
\text { Maximum } \\
\text { Range } \\
\text { Interquartile range } \\
\text { Skewness } \\
\text { Kurtosis }\end{array}$ & $\begin{array}{c}23.78 \\
\text { Lower bound } \\
\text { Upper bound } \\
23.58 \\
20.00 \\
169.495 \\
13.019 \\
0 \\
50 \\
50 \\
20 \\
.216 \\
-.623\end{array}$ & $\begin{array}{l}1.941 \\
19.87 \\
27.69\end{array}$ \\
\hline & Group 2 & $\begin{array}{l}\text { Mean } \\
95 \% \text { CI for mean } \\
5 \% \text { trimmed mean } \\
\text { Median } \\
\text { Variance } \\
\text { SD } \\
\text { Minimum } \\
\text { Maximum } \\
\text { Range } \\
\text { Interquartile range } \\
\text { Skewness } \\
\text { Kurtosis }\end{array}$ & $\begin{array}{c}15.56 \\
\text { Lower bound } \\
\text { Upper bound } \\
14.57 \\
10.00 \\
166.162 \\
12.890 \\
0 \\
60 \\
60 \\
10 \\
1.171 \\
1.889 \\
\end{array}$ & $\begin{array}{l}1.922 \\
11.68 \\
19.43\end{array}$ \\
\hline \multirow[t]{2}{*}{ Post-test } & Group 1 & $\begin{array}{l}\text { Mean } \\
95 \% \text { Cl for mean } \\
\\
5 \% \text { trimmed mean } \\
\text { Median } \\
\text { Variance } \\
\text { SD } \\
\text { Minimum } \\
\text { Maximum } \\
\text { Range } \\
\text { Interquartile range } \\
\text { Skewness } \\
\text { Kurtosis }\end{array}$ & $\begin{array}{c}48.22 \\
\text { Lower bound } \\
\text { Upper bound } \\
47.96 \\
40.00 \\
460.404 \\
21.457 \\
10 \\
90 \\
80 \\
35 \\
.444 \\
-.462 \\
\end{array}$ & $\begin{array}{l}3.199 \\
41.78 \\
54.67\end{array}$ \\
\hline & Group 2 & $\begin{array}{l}\text { Mean } \\
95 \% \text { Cl for mean } \\
\\
5 \% \text { trimmed mean } \\
\text { Median } \\
\text { Variance } \\
\text { SD } \\
\text { Minimum } \\
\text { Maximum } \\
\text { Range } \\
\text { Interquartile range } \\
\text { Skewness } \\
\text { Kurtosis }\end{array}$ & $\begin{array}{c}56.89 \\
\text { Lower bound } \\
\text { Upper bound } \\
57.59 \\
60.00 \\
558.283 \\
23.628 \\
10 \\
90 \\
80 \\
30 \\
-.313 \\
-.689\end{array}$ & $\begin{array}{l}3.522 \\
49.79 \\
63.99\end{array}$ \\
\hline
\end{tabular}

Cl: confidence interval; SD: standard deviation; SE: standard error. 


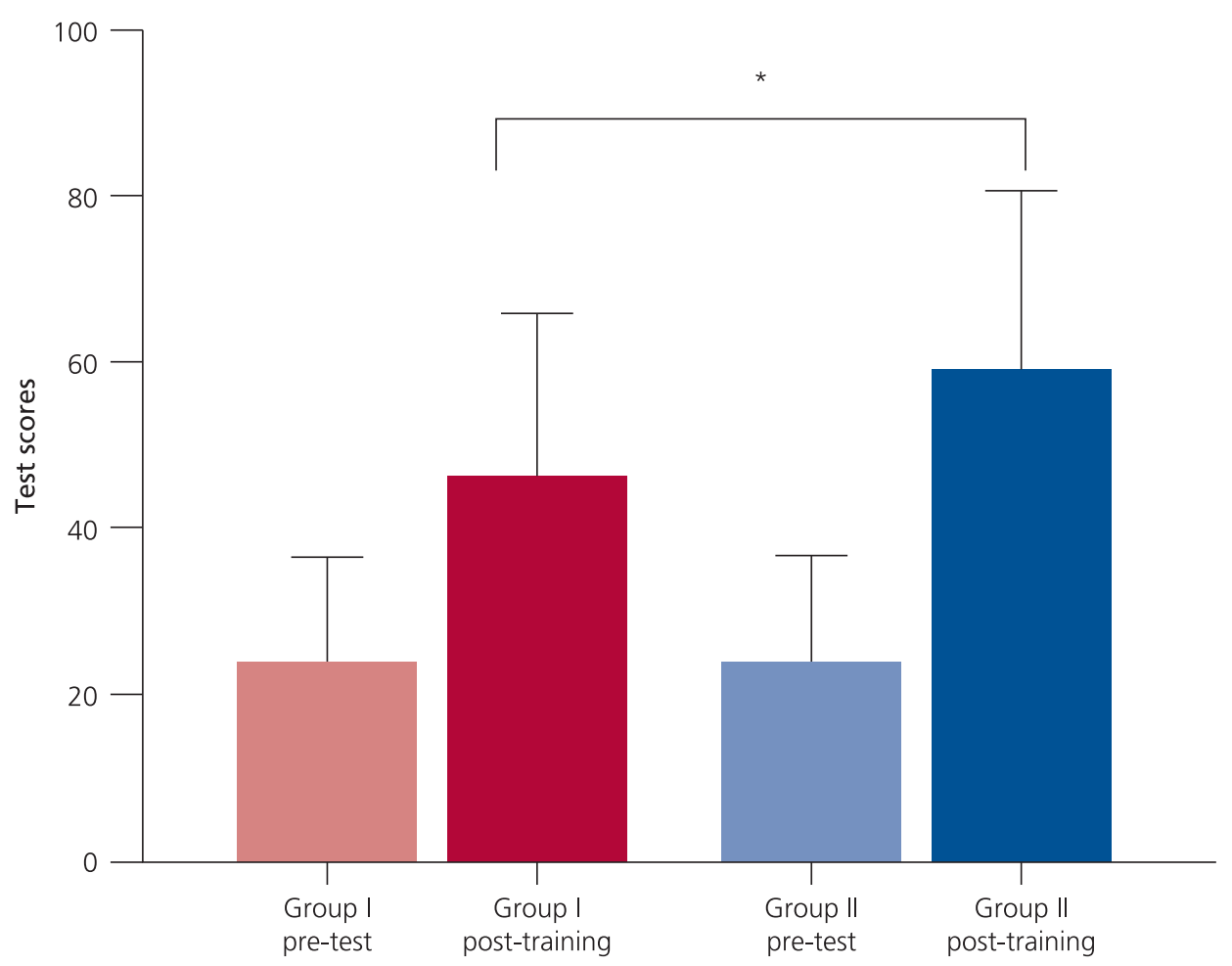

Figure 3. Differences between the groups related to the test scores. Graphs shows pre-test and post-training scores. Group II post-training scores were significantly higher than the group I post-training scores $\left({ }^{*} p<0.05\right)$. The scores of those trained with formalin-fixed specimens and plastinates increased significantly more than the other group $(p=0.0294)$ (One sample paired $t$ test).

nificantly higher than those of the group that received lectures with the only formalin-fixed specimen. The pretest scores of the groups were compared with the scores obtained after the 2 hours lecture $(\mathrm{p}=0.002, \mathrm{p}<0.05)$ (Table 2). It was observed that the test scores of both groups increased significantly after the lecture $(\mathrm{p}=0.047$, $\mathrm{p}<0.05$ ) (Table 2). The average test scores of those trained with formalin-fixed specimens increased from $23.78 \pm 1.94$ to $48.22 \pm 3.19(\mathrm{p}<0.05)$. The average test scores of those trained with both formalin-fixed specimen and plastinates increased from $15.56 \pm 1.92$ to $56.89 \pm 3.52$ $(\mathrm{p}<0.05)$ (Figure 3).

Table 2

The comparison between the groups via test scores.

\begin{tabular}{lcc} 
& \multicolumn{2}{c}{ Test statistics* } \\
\cline { 2 - 3 } & Pre test & Post test \\
\hline Mann-Whitney U & 642.000 & 769.000 \\
\hline Wilcoxon W & 1677.000 & 1804.000 \\
\hline Z & -3.087 & -1.983 \\
\hline Asymp. sig. (2-tailed) & .002 & .047 \\
\hline
\end{tabular}

*Grouping variable: Mann-Whitney U.

\section{Discussion}

Plastination has been the focus of many studies for the last two decades. Some of these studies were related to plastination techniques, ${ }^{[11,12,20]}$ and some of them were related to the importance of plastination in anatomy education. ${ }^{[10,13-15,21]}$ Our study is the first study so far that evaluate if the heart plastinates contribute to anatomy education of the students. Many anatomists prefer plastinates to formalin-fixed cadavers because they are odorless, durable, effortless and easy to handling. ${ }^{[1,1,1,21]}$ Musumeci et al. ${ }^{[2]}$ indicated that plastination is a good tool for dissection and a complementary educational technique that shows different aspects of human anatomy. Riederer stated that plastinates provide a 3-dimensional vision for complex anatomical areas, and a very useful tool for pre- and post-graduate training. ${ }^{[10]}$ Our data showed that education with formalin-fixed cadavers increased students test scores, but the addition of plastinates to the education was significantly increased the success rate. These results indicate that plastinates are useful for teaching the anatomy of the heart, which is a very complex region for the undergraduate medical students.

With its complex anatomy and unique function, the heart has been the subject of various plastination studies 
over the years. ${ }^{[18,23-25]}$ In the 1980 s, the researchers explored how to optimize heart plastinates and to protect the heart's fine structures by plastination. ${ }^{[18,23]}$ Since then, the importance, usefulness and benefits of plastinates have been studied. ${ }^{[24,25]}$ Raoof et al. ${ }^{[25]}$ have performed plastination to demonstrate the function of cardiac valves during systolic and diastolic phases in their study. In this study, a pilot questionnaire was applied to get opinions of the students about plastinates. The results of the survey have shown that most of the students thought heart plastinates are beneficial in terms of demonstrating structural anatomical relationships, learning the anatomy of the heart, understanding function-structure correlation. ${ }^{[25]}$ Since the questionnaire in this study was consisted of only three yes/no type questions, it may not reflect the exact views of the students. However, our study has perceptibly shown that plastinates make easier to learn the anatomy of the heart.

Gomez et al. ${ }^{[2]]}$ have compared heart plastinates and echocardiography images and indicated that plastinated slices were corresponded accurately with the echocardiographic images. They stated that their research could be a reference atlas for assisting $2 \mathrm{D}$ echocardiography interpretation. ${ }^{[2]}$

Plastinates are long lasting, odorless, easy to use, nontoxic and non irritating materials, and these beneficial features have been mentioned in various studies. ${ }^{[1,14,21,26-28]} \mathrm{In}$ our study, besides the increase of success levels, students gave positive feedback about plastinates. They stated that their interest in the lecture increased because plastinates were odorless and easy to handle.

The use of the human body as a cadaver in medical education is a crucial part of anatomy education. ${ }^{[29]}$ When considered in terms of health, formalin could cause eye and skin irritations, degeneration of the mucous membranes, nasopharynx and nasal cavity tumors. ${ }^{[30]}$ Another important issue is the high cost of importing the cadavers of certified donors. In Turkey, body donation is very rare due to cultural structure and majority of the universities are failed to meet the cadaver needs for anatomy training. This problem may common in many countries that have similar culture with Turkey.

COVID-19 outbreak has had serious implications on medical education. In many universities, laboratory lectures are planned to be held in small groups. The transmittion risk of SARS-CoV-2 from cadavers is not known yet. ${ }^{[16]}$ Equipment and material cleaning, as well as individual hygiene, are essential parts of safety during the pandemic. ${ }^{[17]}$ Therefore disinfected and sanitised plastinates could be a good option for the anatomical education during the COVID-19 pandemic when considering their hygienic properties.
Despite all their negative features, formalin fixed cadavers are indispensable for anatomy education. However, it can be beneficial in many ways using plastinates during anatomy education. In their study among medical educators in the USA, Klaus et al. ${ }^{[26]}$ investigated the use and perception of plastination. According to this study results, $100 \%$ of the educators had heard of plastination, $57 \%$ of them correctly defined plastination, and 39\% of them currently utilize plastinates for anatomy education. This study indicated plastinates are used higher than mentioned in the literature in the U.S., but medical anatomy educators perceived plastination as a useful tool, but not a replacement for cadavers. ${ }^{[26]}$

The large scale studies need to investigate the effects of plastinate in anatomy education. Further studies can be supported by plastinates obtained from different regions of the body to improve the quality of anatomy education. The combined evaluation methods can be used to assess the quality of anatomy education with plastinates, or it can be compared using the same techniques for medical students in various schools, regions, or countries.

\section{Conclusion}

Findings of this study with undergraduate first-year medical students at Akdeniz University of School of medicine contributed auxiliary grounds in support of credibility of the plastinated specimens in medical education system. In conclusion, besides being cost-effective, healthy, long lasting and easy to maintain materials, plastinates are useful tools in anatomy education.

\section{Conflict of Interest}

Authors have no conflict of interest to declare.

\section{Author Contributions}

NO, MS and GA: conceived and planned the experiments; GA, EÖ, RS and SG: carried out the experiments; GA and EÖ: contributed to figures and preparation of tables. GA and EÖ: writing the manuscript. All authors contributed to the interpretation of the results, provided critical feedback and helped organizing the research, analysis and manuscript.

\section{Ethics Approval}

The authors certify that the study was performed in accordance with the ethical standards as laid down in the 1964 Declaration of Helsinki and its later amendments. All protocols were approved by the Clinical Research Ethics Committee of Akdeniz University (Number: 70904504-98).

\section{Funding}

The study was funded by the Akdeniz University Scientific Research Projects Coordination Unit, Antalya, TURKEY (Project number: TSA-2015-710). 


\section{References}

1. Yammine K, Violato C. The effectiveness of physical models in teaching anatomy: a meta-analysis of comparative studies. Adv Health Sci Educ Theory Pract 2016;21:883-95.

2. Wilson AB, Miller CH, Klein BA, Taylor MA, Goodwin M, Boyle EK, Brown K, Hoppe C, Lazarus M. A meta-analysis of anatomy laboratory pedagogies. Clin Anat 2018;31:122-33.

3. Cottam WW. Adequacy of medical school gross anatomy education as perceived by certain postgraduate residency programs and anatomy course directors. Clin Anat 1999;12:55-65.

4. Fitzgerald JE, White MJ, Tang SW, Maxwell-Armstrong CA, James DK. Are we teaching sufficient anatomy at medical school? The opinions of newly qualified doctors. Clin Anat 2008;21:718-24.

5. Papa V, Vaccarezza M. Teaching anatomy in the XXI century: new aspects and pitfalls. ScientificWorldJournal 2013;2013:310348.

6. Yammine K, Violato C. A meta-analysis of the educational effectiveness of three-dimensional visualization technologies in teaching anatomy. Anat Sci Educ 2015;8:525-38.

7. Bhangu A, Boutefnouchet T, Yong X, Abrahams P, Joplin R. A three-year prospective longitudinal cohort study of medical students' attitudes toward anatomy teaching and their career aspirations. Anat Sci Educ 2010;3:184-90.

8. Collins JP. Modern approaches to teaching and learning anatomy. BMJ 2008;337:a1310.

9. Estai $M$, Bunt $S$. Best teaching practices in anatomy education: a critical review. Ann Anat 2016;208:151-7.

10. Riederer BM. Plastination and its importance in teaching anatomy. Critical points for long-term preservation of human tissue. $\mathrm{J}$ Anat 2014;224:309-15.

11. Ottone NE, Cirigliano V, Bianchi HF, Medan CD, Algieri RD, Borges Brum G, Fuentes R. New contributions to the development of a plastination technique at room temperature with silicone. Anat Sci Int 2015;90:126-35.

12. Neha, Lalwani S, Dhingra R. Plastinated knee specimens: a novel educational tool. J Clin Diagn Res 2013;7:1-5.

13. O'Sullivan E, Mitchell BS. Plastination for gross anatomy teaching using low cost equipment. Surg Radiol Anat 1995;17:277-81.

14. Latorre R, Bainbridge D, Tavernor A, Lopez Albors O. Plastination in anatomy learning: an experience at Cambridge University. J Vet Med Educ 2016;43:226-34.

15. Ravi SB, Bhat VM. Plastination: A novel, innovative teaching adjunct in oral pathology. J Oral Maxillofac Pathol 2011;15:133-7.

16. Kampf G, Todt D, Pfaender S, Steinmann E. Persistence of coronaviruses on inanimate surfaces and their inactivation with biocidal agents. J Hosp Infect 2020;104:246-51.

ORCID ID:

G. Aytaç 0000-0003-4902-2844; E. Öğüt 0000-0003-2506-9883; R. Şekerci 0000-0002-3253-1186; S. Gürçay 0000-0002-9061-676X; N. Oğuz 0000-0001-6864-8872; M. Sindel 0000-0002-6594-1325
17. WHO Team. Infection prevention and control for the safe management of a dead body in the context of COVID-19. Interim guidance 2020;WHO/2019-nCoV/IPC_DBMgmt/2020.1. CC BY-NC-SA 3.0 IGO, WHO Global. p. 6 .

18. Tiedemann K, von Hagens G. The technique of heart plastination. Anat Rec 1982;204:295-9.

19. Dorri S, Farahani MA, Maserat E, Haghani H. Effect of role-playing on learning outcome of nursing students based on the Kirkpatrick evaluation model. J Educ Health Promot 2019;8:197.

20. Arnts H, Kleinnijenhuis M, Kooloos JG, Schepens-Franke AN, van Cappellen van Walsum AM. Combining fiber dissection, plastination, and tractography for neuroanatomical education: revealing the cerebellar nuclei and their white matter connections. Anat Sci Educ 2014;7:47-55.

21. Latorre RM, Garcia-Sanz MP, Moreno M, Hernandez F, Gil F, Lopez O, Ayala MD, Ramirez G, Vazquez JM, Arencibia A, Henry RW. How useful is plastination in learning anatomy? J Vet Med Educ 2007;34:172-6.

22. Musumeci E, Lang FJW, Duvoisin B, Riederer BM. Plastinated ethmoidal region: I. Preparation and applications in clinical teaching. Journal of the International Society for Plastination 2003;18:23-8.

23. Baptista CAC, Conran PB. Plastination of the heart: preparation for the study of the cardiac valves. Journal of the International Society for Plastination 1989;3:3-7.

24. Gomez A, Del Palacio JF, Latorre R, Henry RW, Sarria R, Albors OL. Plastinated heart slices aid echocardiographic interpretation in the dog. Vet Radiol Ultrasound 2012;53:197-203.

25. Raoof A, Marchese L, Marchese A, Wischmeyer A. Demonstration of systolic and diastolic phases of the cardiac cycle in a plastinated human heart. The Journal of Plastination 2013;25:18-21.

26. Klaus RM, Royer DF, Stabio ME. Use and perceptions of plastination among medical anatomy educators in the United States. Clin Anat 2018;31:282-92.

27. Chaturvedi RK, Singh A, Chaturvedi P, Mishra A, Mishra SP. Advantages of plastinated human body in medical education and its legal \& ethical aspects. Journal of Evolution of Medical and Dental Sciences 2014;3:2626-31.

28. Sivrev DP, Usovich A. Using of plastinated anatomical preparations in preclinical and clinical education of medical students. Acta Morphologica et Anthropologica 2012;19:211-19.

29. Riederer BM. Body donations today and tomorrow: what is best practice and why? Clin Anat 2016;29:11-8.

30. Tanaka K, Nishiyama K, Yaginuma H, Sasaki A, Maeda T, Kaneko SY, Onami T, Tanaka M. Formaldehyde exposure levels and exposure control measures during an anatomy dissecting course [Article in Japanese]. Kaibogaku Zasshi 2003;78:43-51.

Correspondence to: Muzaffer Sindel, MD, PhD, Prof Department of Anatomy, School of Medicine, Akdeniz University, 07070, Antalya, Turkey

Phone: +90 5325620900

e-mail: sindelm@akdeniz.edu.tr

Conflict of interest statement: No conflicts declared.

This is an open access article distributed under the terms of the Creative Commons Attribution-NonCommercial-NoDerivs 4.0 Unported (CC BY-NCND4.0) Licence (http://creativecommons.org/licenses/by-nc-nd/4.0/) which permits unrestricted noncommercial use, distribution, and reproduction in any medium, provided the original work is properly cited. How to cite this article: Aytaç G, Öğüt E, Şekerci, R Gürçay S, Oğuz N, Sindel M. The contribution of plastinates to teaching complex anatomy of the heart. Anatomy 2021;15(1):69-75. 